\title{
Experimental And Numerical Study On Softening And Pinching Effects Of Reinforced Concrete Frame
}

\author{
Mariyana A. Ab-Kadir ${ }^{1}$, J.Zhang ${ }^{2}$, N.Mashros ${ }^{1}$, Abdul Hassan ${ }^{1}$, N.Z Mohd \\ ${ }^{I}$ Faculty of Civil Engineering, Universiti Teknologi Malaysia \\ ${ }^{2}$ School of Engineering, University of Edinburgh
}

\begin{abstract}
The response analysis of reinforced concrete (RC) structures subjected to strong earthquake motions requires material models that are able to simulate cyclic deformation and damage realistically. This paper presents the results of a study of pinching and softening behaviour in an RC frame subjected to cyclic loading. The experiment was conducted on a full-scale RC frame at Indian Institute of Technology Roorkee in India. The hysteretic curve representing the response of the frame was generated. Finite element analyses were performed to predict the response of the frame under cyclic loading both before and after the test using different computer codes, ABAQUS and OpenSees. Although the experiment was conducted using load control, the finite element simulations were performed using displacement control. The result from both models are compared to the experiment and to each other and a detailed discussion is provided on the modelling capabilities of the two software in capturing the pinching and softening behaviour observed in the test.
\end{abstract}

Keywords: - Finite element models, Hysteretic behaviour, Pinching, Softening

\section{INTRODUCTION}

According to present building code, reinforced concrete buildings are designed to withstand certain earthquake intensity and expected to deformed well into the inelastic range and dissipate a large part of the energy input through stable hysteretic behaviour of their structural components [3]. The hysteretic behaviour of the buildings structures reflects the ability of energy dissipation and collapse resistance of a structure at different levels, such a material, member and structure as a whole.

Experimental on single reinforced concrete members is of major importance for understanding the complete structure behaviour subjects to either monotonic or cyclic loading conditions. Even though the experimental do not exactly match the actual condition of members in a real structure, the source of relevant phenomenal remains essentially the same, therefore experimental result could be valuable information on nonlinear response mechanisms. However, experimental for the whole buildings will consume cost and time, therefore numerical analysis is become more applicable.

In over the last two decades, many rigorous and computationally complex methods for predicting of response of reinforced concrete structures subjected to cyclic loading have been developed. The first record of used the nonlinear finite element model (FEM) to simulate reinforced concrete members was in 1967 [8]. The finite element model created broadly to all structure analysis, and not all purposely for an earthquake analysis. Hence, for the general purposes of finite element model for example ABAQUS, SAP2000. It always has to validate with the test data or any finite element model.

In this paper, the response of RC frame subject to cyclic loading is numerically studied using ABAQUS [1] and OpenSees [6]. The results of hysteretic curve from the modeling have been used to compare against experimental result to determine the capability of the modeling

\section{EXPERIMENTAL STUDY}

A single storey of reinforced concrete frame was carried out at Indian Institute of Technology (IIT) Roorkee, India. The height of the frame is $5.0 \mathrm{~m}$ and the distance between plinth beam and roof beam is $3.0 \mathrm{~m}$. The test frame consist of four column with cross-section of the columns is $300 \mathrm{~mm} \times 300 \mathrm{~mm}$ and that of the beams is $230 \mathrm{~mm} \times 230 \mathrm{~mm}$. Slabs thickness is $120 \mathrm{~mm}$. Reinforcing steel details in beam and column as shows in Figure 1 and 2. The frame was subjected to cyclic lateral load in load control manner using pair of double acting hydraulics jack acting in tendem with each other against a stiff reaction wall at the slab level of the frame [9]. Front view of schematic test frame as shows in Figure 3. Each column was loaded with an 80kN load coming from upper storey and the slab was loaded with a uniformly distributed load of $2.3 \mathrm{kN} / \mathrm{m}^{2}$. 


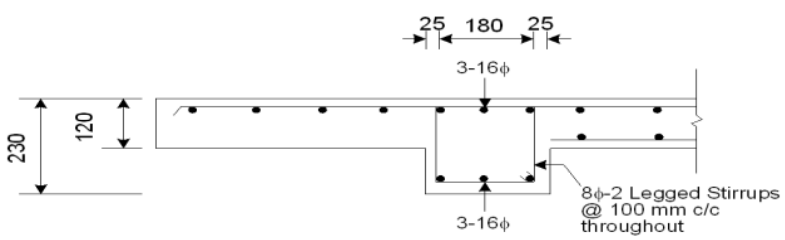

Figure 1. Detailing of beam reinforcement

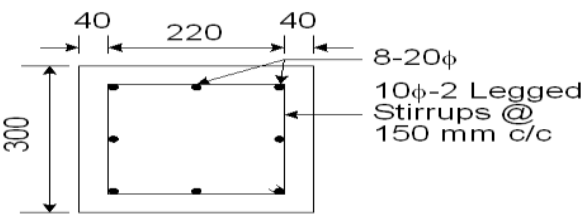

Figure 2. Detailing of column reinforcement

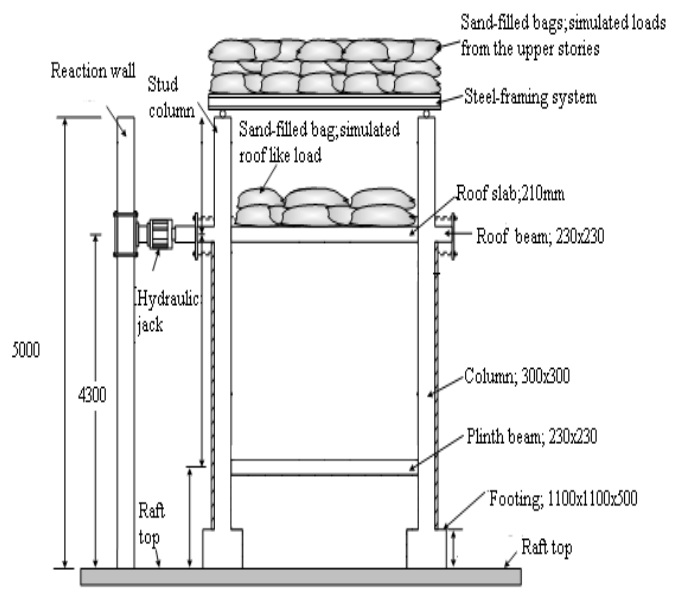

Figure 3. Schematic of the test frame and loading arrangement

\section{FINITE ELEMENT ANALYSIS}

To study the behaviour of RC frame under earthquake excitation loading, the numerical modeling of the $\mathrm{RC}$ frame was investigated. The numerical analysis was carried out using the general purpose of finite element software ABAQUS and the open source software framework OpenSees.

A 2D beam element is modeled using ABAQUS. All the elements are simulated using beam elements. In order to reduce computational time the slab was modelled as apart of the overall beam cross section in $2 \mathrm{D}$ beam element model. Timoshenko beam element (B21) that allows transverse shear strain is used in this. The 2D beam element model of RC frame as shows in Figure 4. The compressive strength of concrete is 34MPa and tensile strength is 3.4MPa. Material properties is used according to Eurocode [2]. The stress-strain relationship for both concrete and reinforcing steel as shows in Figure 5 and 6 . Continuum plasticity - based damage model known as concrete damaged plasticity in ABAQUS is used to simulate the behaviour of concrete. The concrete damage plasticity model take into consideration of degradation of strength of the concrete under both compression and tension. It assumes that the two main failure mechanisms are tensile cracking and compressive crushing of the concrete material and that the uniaxial tensile and compressive response of concrete is characterized by damaged plasticity[4]. Due to the limitation of using shell element in simulation of the pinching and softening effects, the structural response will be compared with the results using OpenSees.

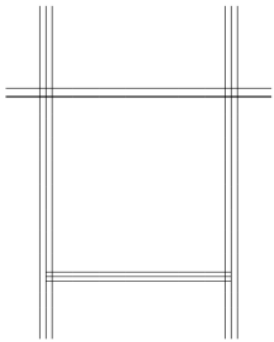

Figure 4. 3D shell element model 


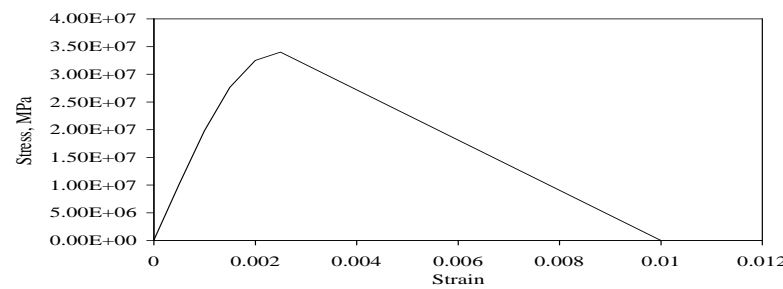

Figure 5. Stress strain relationship of concrete

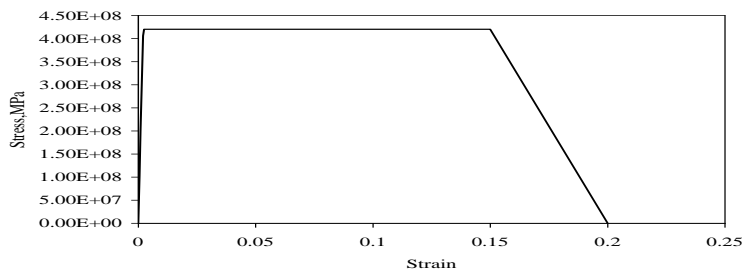

Figure 7. Stress strain relationship of reinforcing steel

In OpenSees, Euler- Bernoulli beam element is used to model the RC frame. To take into account the pinching and softening behaviour, pinching material have been used at the end of the joint. The pinching material is a uniaxial material that represents a 'pinched' load-deformation response and exhibits degradation under cyclic loading. Cyclic degradation of strength and stiffness occurs in three ways: unloading stiffness degradation, reloading stiffness degradation, strength degradation [7,5]. The degradation of the stiffness and strength of the pinching material under cyclic loading is shown in Figure 7

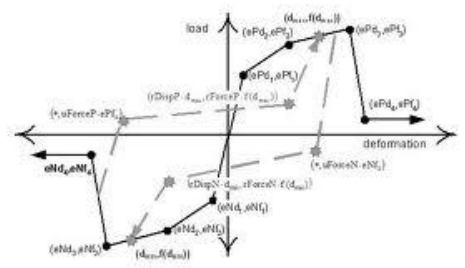

Figure 8. . Pinching material in OpenSees

\section{CYCLIC LOADING ANALYSIS}

In numerical analysis, the displacement control scheme was used to generate hystretic behaviour of the frame. A step-by step procedure in increasing displacement to reach the maximum displacement capacity (about $90 \mathrm{~mm}$ ) obtained the hysteretic behavior the frame. The displacement is applied the slab level of the frame. The displacement history applied as shows in Figure 8.

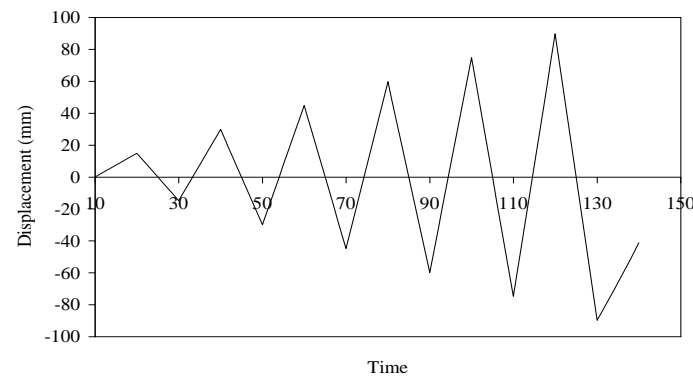

Figure 9. Displacement history

Figure 9 is illustrates the hysteretic behavior of the frame obtained in the test. Stiffness degradation and pinching effects clearly shows in the curve. Figure 10 and 11 shows the hysteretic curve of the frame obtained from ABAQUS and OpenSees, respectively. 


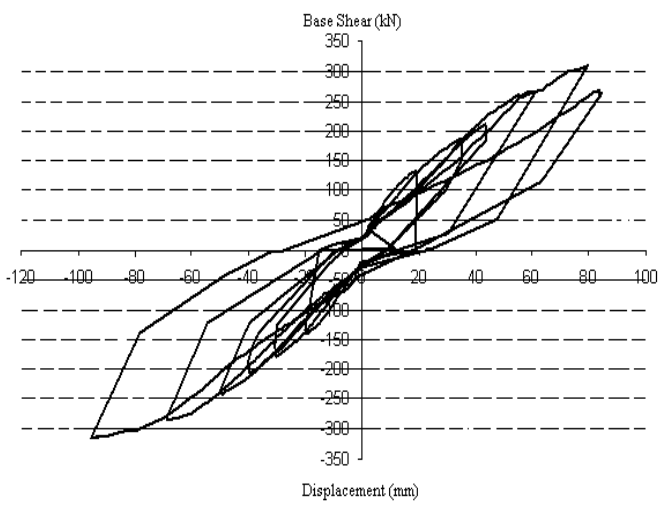

Figure 10. Hysteretic curve of tested frame

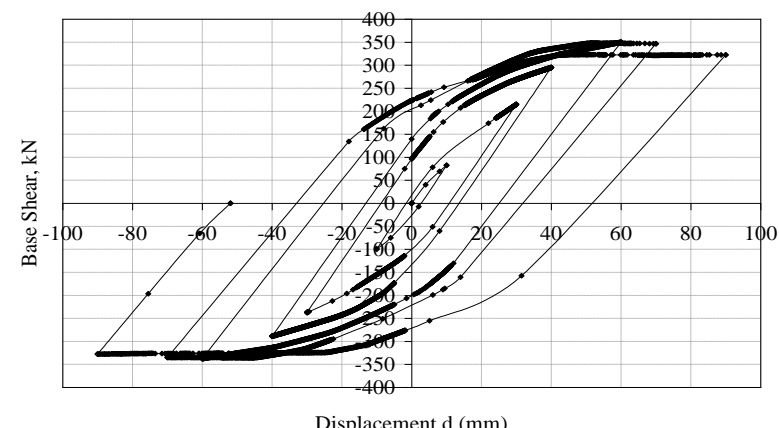

Figure 11. Hysteretis curve of ABAQUS analysis

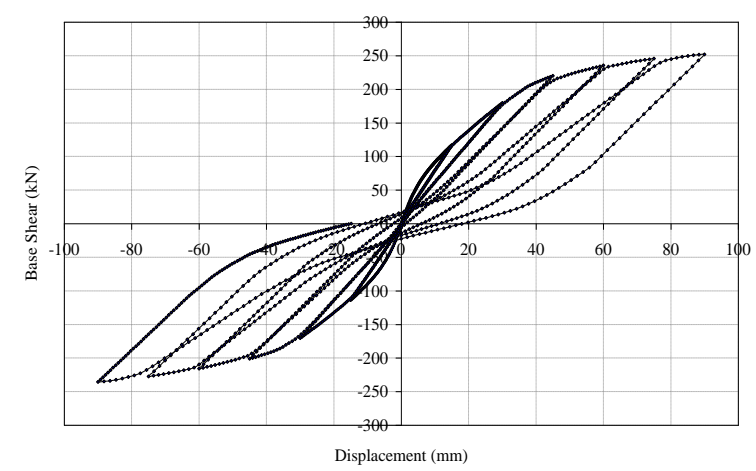

Figure 10. Hysteretis curve of OpenSees analysis

From the figure, it can be clearly observed that the results obtained from ABAQUS can find the strength envelop (or capacity curve) precisely .But, when the deformation increases, the area under the loop varies dramatically. OpenSees results can simulate the hysteretic behavior much better than ABAQUS.

\section{SUMMARY AND CONCLUSION}

From this study, it is found that by using numerical simulation to study the cyclic response of RC frame, OpenSees can take both pinching and softening effect into account. The hysteresis curve looks close using OpenSees than using ABAQUS. By using ABAQUS, the beam element was used to simulate the RC frame behaviour. However this type of element shows the effects of strength and stiffness degradation but not reflect the pinching behaviour

\section{ACKNOWLEDGMENT}

This studies which are presented herein have been carried out as part of a research project involving the University of Edinburgh and Indian Institute of Technologi (IIT) Roorkee, India. Thanks to the researchers from Department of Civil Engineering, IIT Roorkee for providing the testing results of full-scale RC frame. 


\section{REFERENCES}

[1] ABAQUS, ABAQUS 6.8 (2008) Dassault Systemes Simulia Corp: Providence

[2] EN1992-1-2: Eurocode 2 (2004) Design of concrete structures

[3] Filip C.F, and Issa A. (1988) Nonlinear Analysis of Reinforced Concrete Frames Under Cyclic load Reversals. Report No. UCB/EERC-88/12, Earthquake Engineering Research Center, University of California Berkeley

[4] Lee, J., and G. L. Fenves (1998) Plastic-Damage Model for Cyclic Loading of Concrete Structures, Journal of Engineering Mechanics, 124: 892-900

[5] http://nisee.berkeley.edu/elibrary/Text/1288878

[6] http://opensees.berkeley.edu

[7] http://opensees.berkeley.edu/wiki/index.php/OpenSees_User

[8] Ngo, D. and Scordelis, A.C. (1967) Finite Element Analysis of Reinforced Concrete Beams, Journal of ACI,64: 152-163.

[9] Sharma, U.K. et. al., Full scale testing of a damaged RC frame in fire, Structures and Buildings, Proceedings of the ICE, in press, 2012 